Supporting information for:

\title{
Design Considerations for RNA Spherical Nucleic Acids (SNAs)
}

\author{
Stacey N. Barnaby ${ }^{1,2}$, Grant Perelman ${ }^{1,2}$, Kevin L. Kohlstedt ${ }^{1}$, Alyssa B. Chinen ${ }^{1,2}$, \\ George C. Schatz ${ }^{1,2}$, Chad A. Mirkin*1,2 \\ ${ }^{1}$ Department of Chemistry, Northwestern University, 2145 Sheridan Road, Evanston, \\ Illinois 60208, United States; ${ }^{2}$ International Institute for Nanotechnology, Northwestern \\ University, 2145 Sheridan Road, Evanston, Illinois 60208, United States; \\ *To whom correspondence should be addressed \\ E-mail: chadnano@,northwestern.edu \\ Phone: 847.467.7302
}

\section{SI Discussions}

\subsection{Difference in Density Between DNA and RNA on Nanoparticle Surfaces}

It has been observed that the density of propylthiol-modified RNA with gene regulatory sequences on gold nanoparticle surfaces is lower than hexylthiol- modified DNA ( $25 \mathrm{pmol} / \mathrm{cm}^{2}$ for the thiolated single stranded RNA (ssRNA) oligonucleotide with a hexaethylene glycol spacer on a $13 \mathrm{~nm}$ particle ${ }^{1}$ versus $38-56 \mathrm{pmol} / \mathrm{cm}^{2}$ for the thiolated ssDNA oligonucleotide with a hexaethylene glycol or a ten thymine $\left(\mathrm{T}_{10}\right)$ nucleobase spacer on a $15 \mathrm{~nm}$ nanoparticle (different sequence) functionalized with ssDNA). ${ }^{2}$ It is hypothesized that the difference in loading is due to differences in flexibility associated with the 2'-hydroxyl (2'-OH) group, leading to conformational switches in RNA not present in DNA and allowing RNA to adopt structures with larger footprints than analogous DNA structures. ${ }^{3}$ For specifically designed propylthiol DNA and RNA sequences, comparable densities on $10 \mathrm{~nm}$ gold nanoparticles have been measured (75 and $55 \mathrm{pmol} / \mathrm{cm}^{2}$, respectively). ${ }^{4}$

\subsection{Explanation of Block siRNA}

The 3'- 5' UAUGC block was selected as our reference motif (SNA-3, Block 1) as it is the motif closest to the nanoparticle surface in SNA-3. The order of the nucleobases was not altered in each block, only the absolute distance of the block from the nanoparticle surface. Specifically, in SNA-4 (Block 2), the UAUGC motif was in the second position, in SNA-5 (Block 3) the third position, and in SNA-6 (Block 4), the fourth position. Interactions with $10 \% \mathrm{FBS}$ revealed that this movement had a drastic effect on the AS RNA half-life on the nanoparticle surface. Although future work is needed to establish the relationship between distance of this motif from the nanoparticle surface and stability, these data point to a correlation between increase in stability as the $\mathrm{UA} / \mathrm{AU}$ motif is moved further from the nanoparticle surface. 


\subsection{Additional Information on Molecular Dynamics Simulations}

We have generated SNA-RNA conformations via molecular dynamics trajectories using a detailed electrostatic coarse-grained RNA model based on a previous DNA beadspring model. ${ }^{5}$ In this work we are interested in the structural thermodynamics of tethered RNA (tRNA) loaded onto a $13 \mathrm{~nm}$ gold nanoparticle at high loading densities (88 strands). The coarse grained model is able to treat high tRNA loading densities, where the concentration of the counterions ( $\mathrm{r}$ ) is quite high $\sim 300-700 \mathrm{mM}$ and a weak electrostatics treatment such as simple Debye screening is no longer appropriate. Further, the entropic penalty of the complementary free RNA (cfRNA) strands bringing more counterions to the nanoparticle needs to be accounted for in the binding thermodynamics. For these reasons, we have utilized the CG DNA model that explicitly includes tDNA hybridization/melting and have modified it for use with RNA-SNAs. All hydration forces (entropic and enthalpic) are implicitly included in order to keep the model tractable.

The tRNA and cfRNA are described by the following Hamiltonian:

$$
\begin{aligned}
& H_{D N A}=\sum_{b}^{N b} \frac{k_{b}}{2}\left(r_{b}-l\right)^{2}+\sum_{a}^{N a} \frac{k_{\theta}}{2}\left(\theta_{a}-\theta_{0}\right)^{2}+\sum_{i, j \notin b_{i} a}^{N} \frac{1}{4 \pi \varepsilon_{0}} \frac{q_{i} q_{j}}{r_{i j}}+ \\
& \sum_{i_{i} j \notin b_{i} a}^{N} 4 \varepsilon\left[\left(\frac{\sigma}{r_{i j}}\right)^{12}-\left(\frac{\sigma}{r_{i j}}\right)^{6}\right]+U_{i o n s}
\end{aligned}
$$

where $b$ and $a$ is the bond and angle between adjacent beads $(i, j,(k))$ and $U_{\text {ions }}$ is the interaction between the RNA and free ions. $N_{b}, N_{a}$, and $N$ are the number of bonds, angles, and beads in the model. The first term represents: (1) the phosphodiester bond along the DNA backbone, and (2) the thiolate bond between the PEG spacer and the gold surface. The second term is the three-body angle term that accounts for the stiffness of the chain. The three-body angle constant $k_{\mathrm{q}}$ was stiffened slightly to $8 k_{B} T$ in the RNA model, since the stiffness of RNA is $10-15 \%$ more than DNA. ${ }^{6}$ The third term is the Coulomb interaction between the $(-1 e)$ charged backbone beads (excluding bonded neighbors and next-nearest neighbors in angles). A uniform dielectric of $\mathrm{e}=78$ was used in all simulations to screen the charges in an aqueous environment. The fourth term is a Lennard-Jones (LJ) potential to account for the excluded volume of each RNA bead, as well as for the short-range attraction of complementary pairs of RNA beads (see Fig. S3 and Table S3). The LJ potential is also excluded in bonded, neighboring beads. Noncomplementary beads interact via the Weeks-Chandler-Andersen (WCA) potential, ${ }^{7}$ which is just the LJ potential shifted to zero at $r=r_{\min }=2^{1 / 6} \mathrm{~s}$. The final term is the interaction between the DNA beads and the free ions: $\mathrm{Na}^{+}$counterions and $\mathrm{Cl}^{-}$co-ions. $U_{\text {ions }}$ is of the form of the second and third terms in $H_{D N A}$, except no bonds and angles are excluded.

The RNA model has been used to previously predict the thermodynamics of DNA hybridization on SNA targets, phase diagram of multiparticle SNA assemblies, ${ }^{8,6}$ predict design rules and melting properties of DNA linked prisms, ${ }^{9}$ and crystallization of DNA linked nanocubes. ${ }^{10}$ The parameters used for the PEG spacer, tRNA and cfRNA are shown in Table S2. All Au-Au bonds were constrained using rigid body dynamics. ${ }^{11}$ 


\subsection{Additional Information on the Conical Cell Model}

The conical model is shown in Figure S10. Briefly, the order parameter is widely used in the liquid crystalline literature and can be related to the the Legendre polynomial of the cosine of the deviation from a director or

$$
\mathrm{S}=\mathrm{P}_{2}(\cos \varphi)
$$

where $\mathrm{P}_{2}$ is the second Legendre polynomial (see Figure S10). The director is the normal vector based on the surface of Au core where the RNA is tethered. The average $\left\langle\mathrm{R}_{\mathrm{G}}>\right.$ can be related to a conical cell model and used to calculate the average footprint of each RNA strand (Figure S10). Since the duplexed RNA behaves like a semi-flexible rod, we use the end-to-end length $\langle\mathrm{L}\rangle$ and director angle $\langle\varphi\rangle$, where $\langle\ldots\rangle$ represents the ensemble average, to parametrize the length and radii of the conical frustum. A conical frustum is used here for two reasons: (1) A dsRNA and coiled ssRNA trace-out a conical footprint and (2) The different spacer lengths directly affect the RNA footprint, which is captured by the radius of both the inner and outer frustum. For example, we find that the average cell size $\left(D_{o}\right)$ for a $40 \%$ duplexed RNA-SNA with Sp1 is $7.99 \pm 1.43 \mathrm{~nm}$ for ssRNA, while for $\mathrm{Sp} 0$ it is $4.10 \pm 1.21 \mathrm{~nm}$. For dsRNA, we find $11.30 \pm 2.27 \mathrm{~nm}$ and $8.29 \pm 1.83$ $\mathrm{nm}$ for $\mathrm{Sp} 1$ and $\mathrm{Sp} 0$, respectively. Surprisingly, we find that when comparing the total amount of surface area available, the Sp0 RNA-SNA has a $17 \%$ increase in the amount of cross-sectional space available even when accounting for the smaller overall size of the RNA with Sp0.

\subsection{Different SNA Backfills Explored}

We investigate and compare four different polymeric and DNA backfills for two different SNAs, using SNA-7 as a representative sequence with the longest half-life (Figure S8a-d) and SNA-3 as a representative sequence with a short half-life (Figure S8eh). We observed that backfilling SNA-7 with PEG $2 \mathrm{~K}$, resulted in the longest AS oligonucleotide half-life of the backfills investigated, whereas for SNA-3, the backfill did not have any measurable effect on increasing RNA half-life. For sequences with $3^{\prime}-5^{\prime} / 5^{\prime}-$ $3^{\prime}$ motifs of UA/AU close to the nanoparticle surface, the identity of the backfill does not appear to affect the rate of enzymatic recognition, but for sequences without this motif, the backfill may play a small role in modulating the rate of enzymatic activity. We hypothesize that when a motif that is rapidly degraded by serum nucleases is present close to the nanoparticle surface, the backfill is not enough to prevent degradation from happening, as there is enough room on the nanoparticle surface for this to occur. But in the case of SNA-7, we start to see differences in the response to the backfill. We hypothesize that this may be due to differences in densities of the backfills on the nanoparticle surface (similar to what was observed for backfill incubation time in Figure $5 \mathrm{~b}$, c versus Figure $2 \mathrm{a}, \mathrm{b}$ ) and future work is ongoing to that point. 


\begin{tabular}{|c|c|c|c|}
\hline$\#$ & Target mRNA (For sequences 1-3 and 7-10) & Identity & Sequence $\left(3^{\prime}-5^{\prime} / / 5^{\prime}-3^{\prime}\right)$ \\
\hline 5 & $\begin{array}{c}\text { mGM3S 697 } \\
\text { (697) } \\
\text { mGM3S 799 } \\
\text { (799) } \\
\text { Androgen Receptor } \\
\text { (AR) } \\
\text { Androgen Receptor Block } 2 \\
\text { (AR_Block 2) } \\
\text { Androgen Receptor Block 3 } \\
\text { (AR_Block 3) } \\
\text { Androgen Receptor Block 4 } \\
\text { (AR_Block 4) } \\
\text { Methylguanine Methyltransferase } \\
\text { (MGMT) } \\
\text { (STAT3) } \\
\text { Signal Transducer and Activator of Transcription 3 } \\
\text { Vascular Endothelial Growth Factor } \\
\text { (VEGFC) } \\
\text { Yellow Fluorescent Protein } \\
\text { (YFP) }\end{array}$ & $\begin{array}{l}\text { Sense } \\
\text { Anti-Sense (AS) } \\
\text { Sense } \\
\text { Anti-Sense (AS) } \\
\text { Sense } \\
\text { Anti-Sense (AS) } \\
\text { Sense } \\
\text { Anti-Sense (AS) } \\
\text { Sense } \\
\text { Anti-Sense (AS) } \\
\text { Sense } \\
\text { Anti-Sense (AS) } \\
\text { Sense } \\
\text { Anti-Sense (AS) } \\
\text { Sense } \\
\text { Anti-Sense (AS) } \\
\text { Sense } \\
\text { Anti-Sense (AS) } \\
\text { Sense } \\
\text { Anti-Sense (AS) }\end{array}$ & 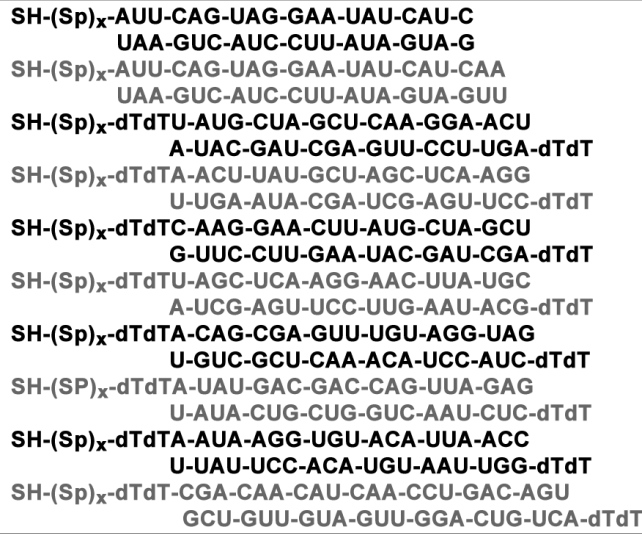 \\
\hline
\end{tabular}

Table S1: Complete list of siRNA duplexes used in this study. Nanoparticles were functionalized with the above RNA duplexes. The origin of each sequence is referenced above. 


\begin{tabular}{|l|l|}
\hline Parameter & Value \\
\hline$l$ (RNA-RNA) & $3.4 \AA$ \\
\hline$k_{\mathrm{b}}$ (RNA-RNA) & $330 k_{B} T$ \\
\hline$l$ (Sp-RNA) & $4.8 \AA$ \\
\hline$l$ (Sp-Au) & $4.4 \AA$ \\
\hline$k_{\mathrm{b}}$ (RNA-Sp) & $330 k_{B} T$ \\
\hline$k_{\mathrm{q}}$ (RNA-RNA-RNA) & $7 k_{B} T$ \\
\hline$k_{\mathrm{q}}(\mathrm{Au}-\mathrm{Sp}-\mathrm{Sp})$ & $0 k_{B} T$ \\
\hline$\varepsilon R N A-R N A$ (non-complimentary) & $1 k_{B} T$ \\
\hline$\varepsilon R N A-R N A$ (complimentary) & $4.35 k_{B} T$ \\
\hline$\varepsilon R N A-x$ & $1 k_{B} T$ \\
\hline$s R N A-[N a, C l]$ & $5.44 \AA$ \\
\hline$s R N A-R N A$ & $7.48 \AA$ \\
\hline$s R N A-A u$ & $6.3 \AA$ \\
\hline$s$ Au- $A u$ & $5.1 \AA$ \\
\hline$s S p-S p$ & $2.0 \AA$ \\
\hline$s[N a, C l]-[N a, C l]$ & $3.4 \AA$ \\
\hline$N_{\text {beads }}(t R N A)$ & 22 beads $(21$ binding region) \\
\hline$N_{\text {beads }}(c f R N A)$ & \\
\hline
\end{tabular}

Table S2: Details of the worm-like chain (WLC) model and parameters used in RNA MD simulations 

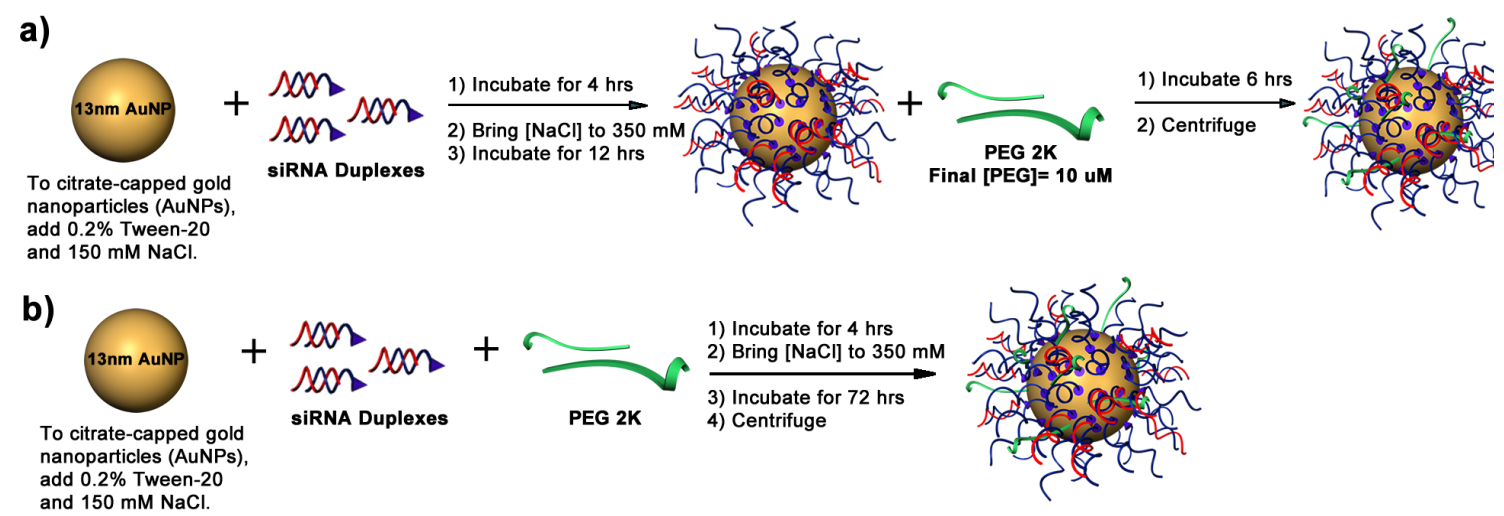

\section{Figure S1: Synthetic schemes for SNA synthesis}

a) This method is used synthesize SNAs-1 through 10. SNA 7-1 was synthesized by a modification of this method that included a 72-hour thiolated $2 \mathrm{kDa}$ polyethylene glycol incubation. Derivatives of SNA-3 and SNA-7 (Figure S12) were synthesized by modification of this method, where PEG2K was replaced with OEG, a thiolated $5 \mathrm{kDa}$ PEG (PEG5K), or a thiolated DNA sequence of twenty thymine nucleobases $\left(\mathrm{T}_{20}\right)$.

b) This new SNA synthesis scheme is used to control both the amount of sense oligonucleotide and backfill on the nanoparticle surface by adding both the RNA duplexes and the backfill molecule simultaneously. To do so, SNA 7-2 employed a 1:10 ratio of RNA:PEG $2 \mathrm{~K}$.

Two different synthetic schemes were utilized because it is difficult to change the density of sense and AS oligonucleotides using the procedure in Figure S1a, because the duplex is pre-hybridized before chemisorbing to the nanoparticles, and thus one has little control over the amount of oligonucleotides that become immobilized on the nanoparticle surface. Therefore, to control the density of immobilized RNA, other synthetic methods can be used such as the method detailed in Figure S1b to control the sense oligonucleotide loading. 


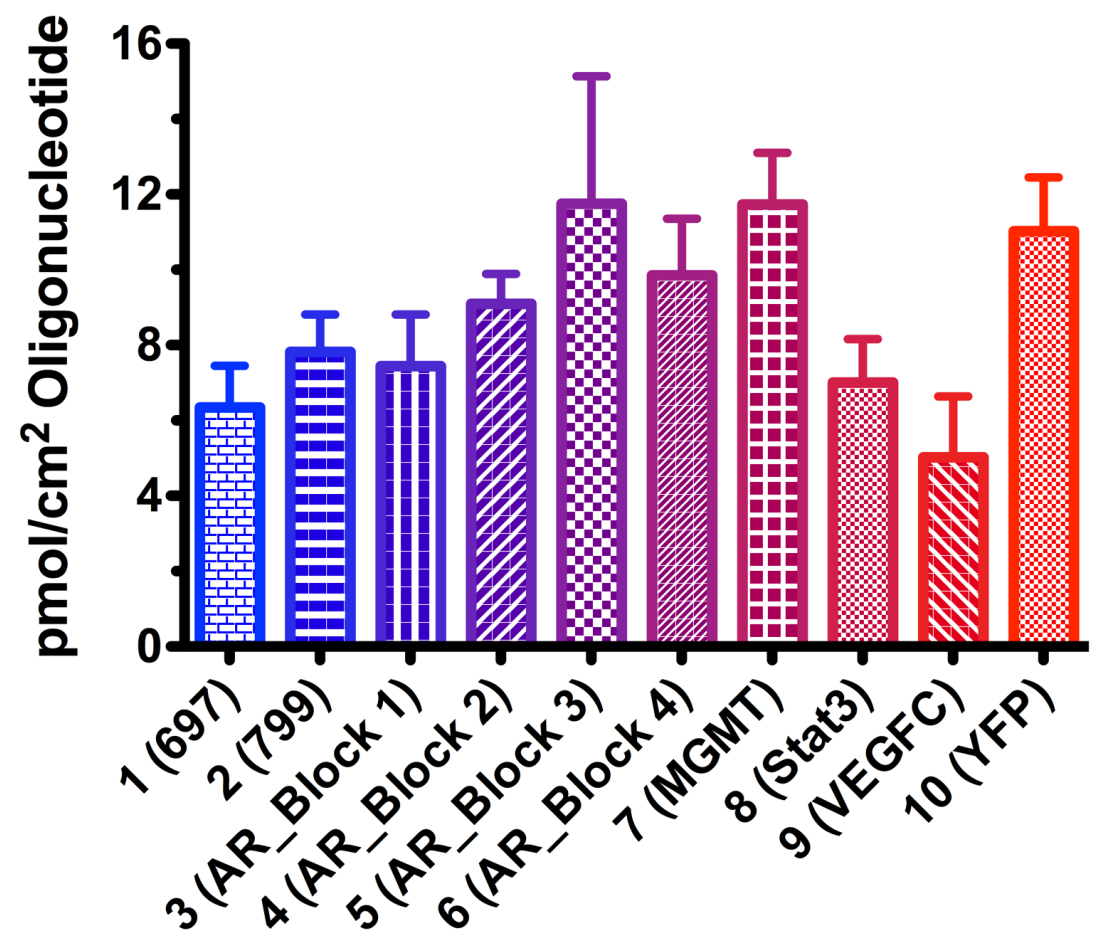

Figure S2: AS oligonucleotide loading for SNAs 1-10. Errors bars represent the standard deviation from $\mathrm{n}=3$ measurements. Data for SNA-3 (AR) is adapted from Barnaby et al. ${ }^{1}$ 


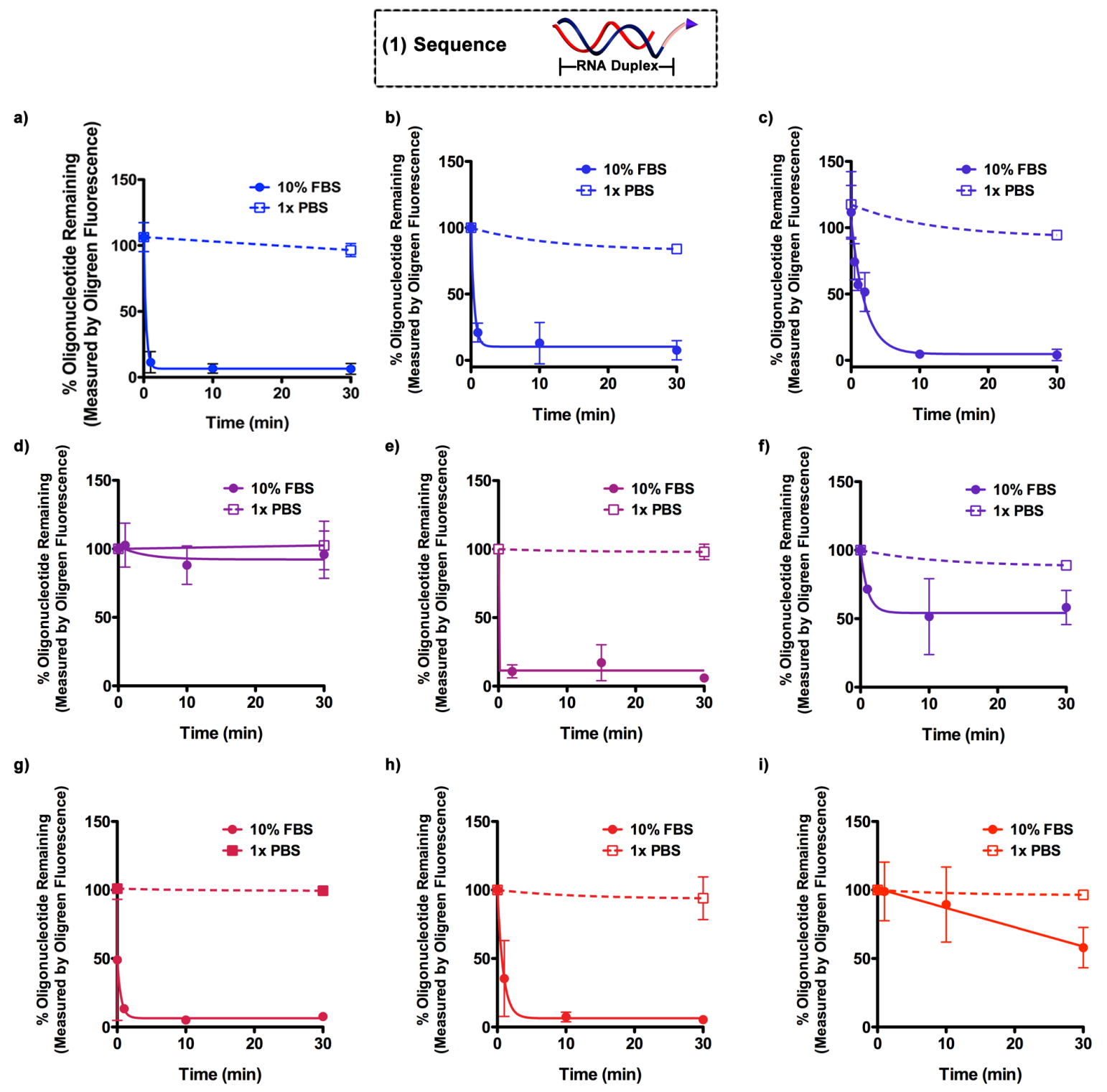

Figure S3: How sequence affects nuclease-catalyzed hydrolysis

The half-lives in Figure $2 \mathrm{~b}$ were measured by fitting each of the experimental points above to a first order decay function. Parallel reactions were also performed in $1 \mathrm{x}$ phosphate buffered saline (PBS) to confirm that the loss of the AS olignucleotide is due to serum nucleases, and not any experimental error. The samples in 1x PBS display essentially no loss in the amount of AS oligonucleotides. Error bars represent the standard deviation for $n=3$ biological replicates in $10 \%$ FBS and $n=2$ biological replicates in 1x PBS. This confirms serum nucleases as the source of nuclease catalyzed hydrolysis for the following SNAs: a) SNA-1 (697); b) SNA-2 (799); c) SNA-3 (AR); Adapted from Barnaby et al; ${ }^{1}$ d) SNA-4 (AR_Block 2); e) SNA-5 (AR_Block 3); f) SNA6 (AR_Block 4); g) SNA-8 (Stat3); h) SNA-9 (VEGFC); i) SNA-10 (YFP). 


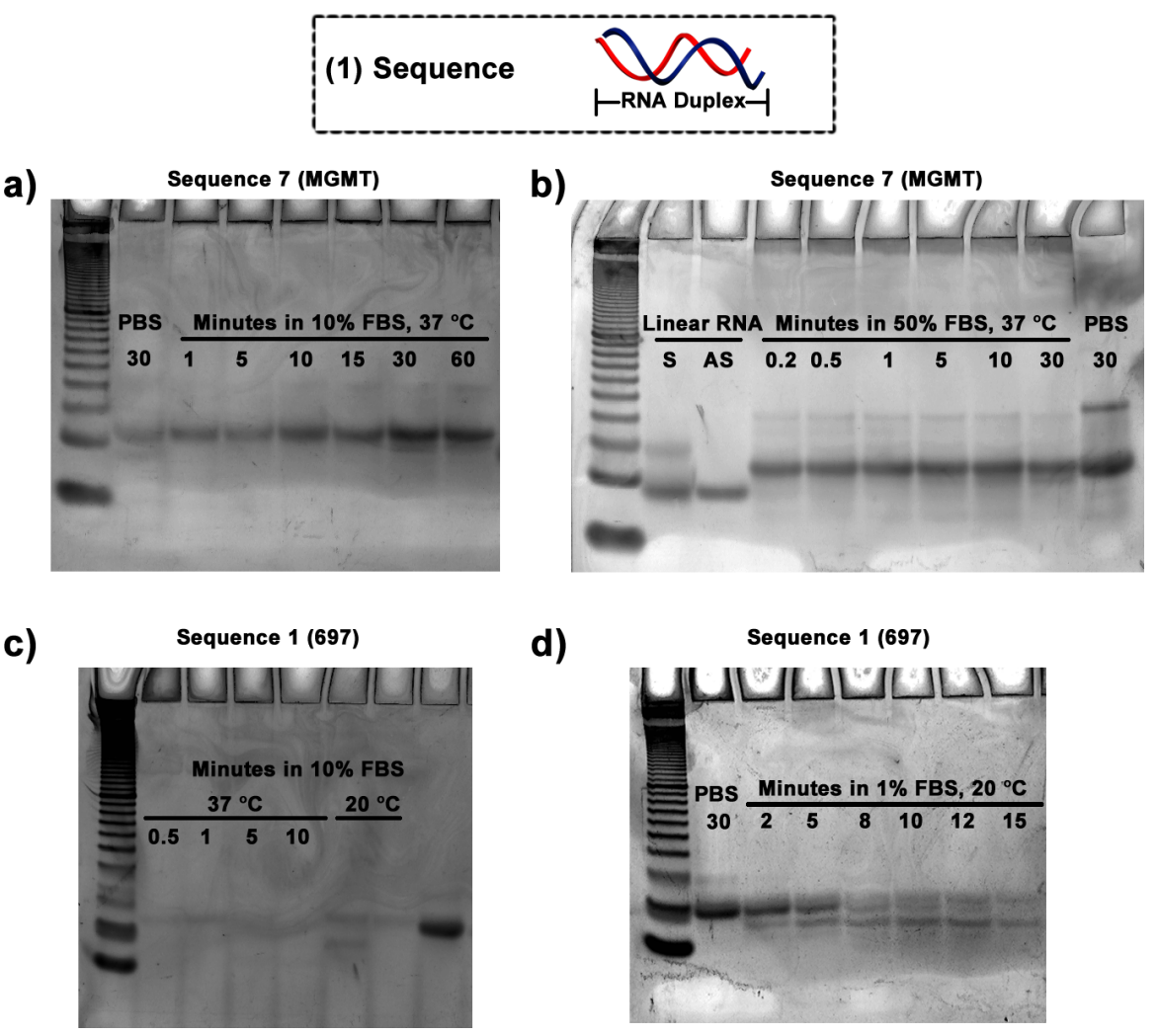

Figure S4: The effect of sequence on the rate of nuclease-catalyzed hydrolysis for free linear duplexes of RNA

a) Duplexes of Sequence 7 in $10 \% \mathrm{FBS}$ at $37{ }^{\circ} \mathrm{C}$ for 0 to $60 \mathrm{~min}$. The duplex band is present throughout the duration of the experiment. Lower bands start to appear after $30 \mathrm{~min}$.

b) Duplexes of Sequence 7 in $50 \% \mathrm{FBS}$ at $37{ }^{\circ} \mathrm{C}$ for 0 to $60 \mathrm{~min}$. The duplex band is present throughout the duration of the experiment. Lower bands start to appear after 1 $\min$.

c) Duplexes of Sequence 1 in $10 \% \mathrm{FBS}$ at $37^{\circ} \mathrm{C}$ and $20{ }^{\circ} \mathrm{C}$ for 0 to $10 \mathrm{~min}$. The duplex band is not present at $37^{\circ} \mathrm{C}$. At $20^{\circ} \mathrm{C}$, the duplex band is not observed after 1 minute.

d) Duplexes of Sequence 1 in $1 \% \mathrm{FBS}$ at $20{ }^{\circ} \mathrm{C}$ for 0 to $15 \mathrm{~min}$. The duplex band is present throughout and grows less in intensity as time is increased and lower bands start to appear. 

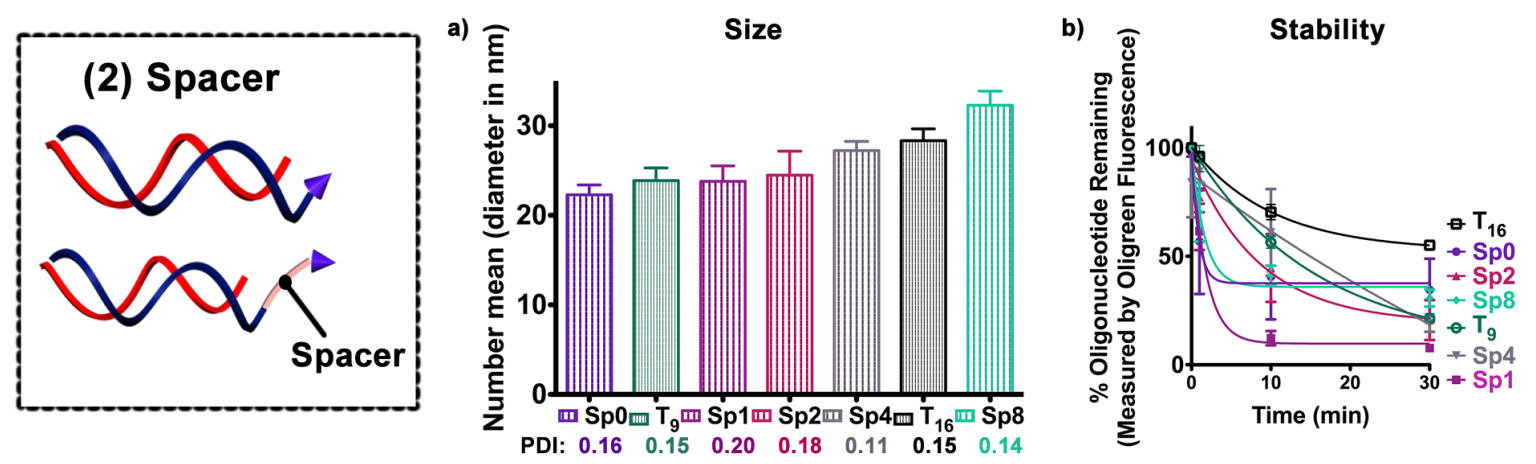

Figure S5: How the spacer affects the oligonucleotide density and stability of SNA-7

a) Sense and anti-sense oligonucleotide loading per $13 \mathrm{~nm}$ gold nanoparticle for MGMT RNA. The density of sense oligonucleotides per nanoparticle was measured to be $\approx 25 \mathrm{pmol} / \mathrm{cm}^{2}$ and the density of sense oligonucleotides per nanoparticle was measured to be between 7 and $12 \mathrm{pmol} / \mathrm{cm}^{2}$.

b) Plot of $\%$ oligonucleotide remaining vs. time ( $\mathrm{min}$ ) for SNA-7 with different spacer motifs. This is the raw data for the half-life plot in Figure 3c. Error bars represent the standard deviation in each time point for $\mathrm{n}=3$ biological replicates. 

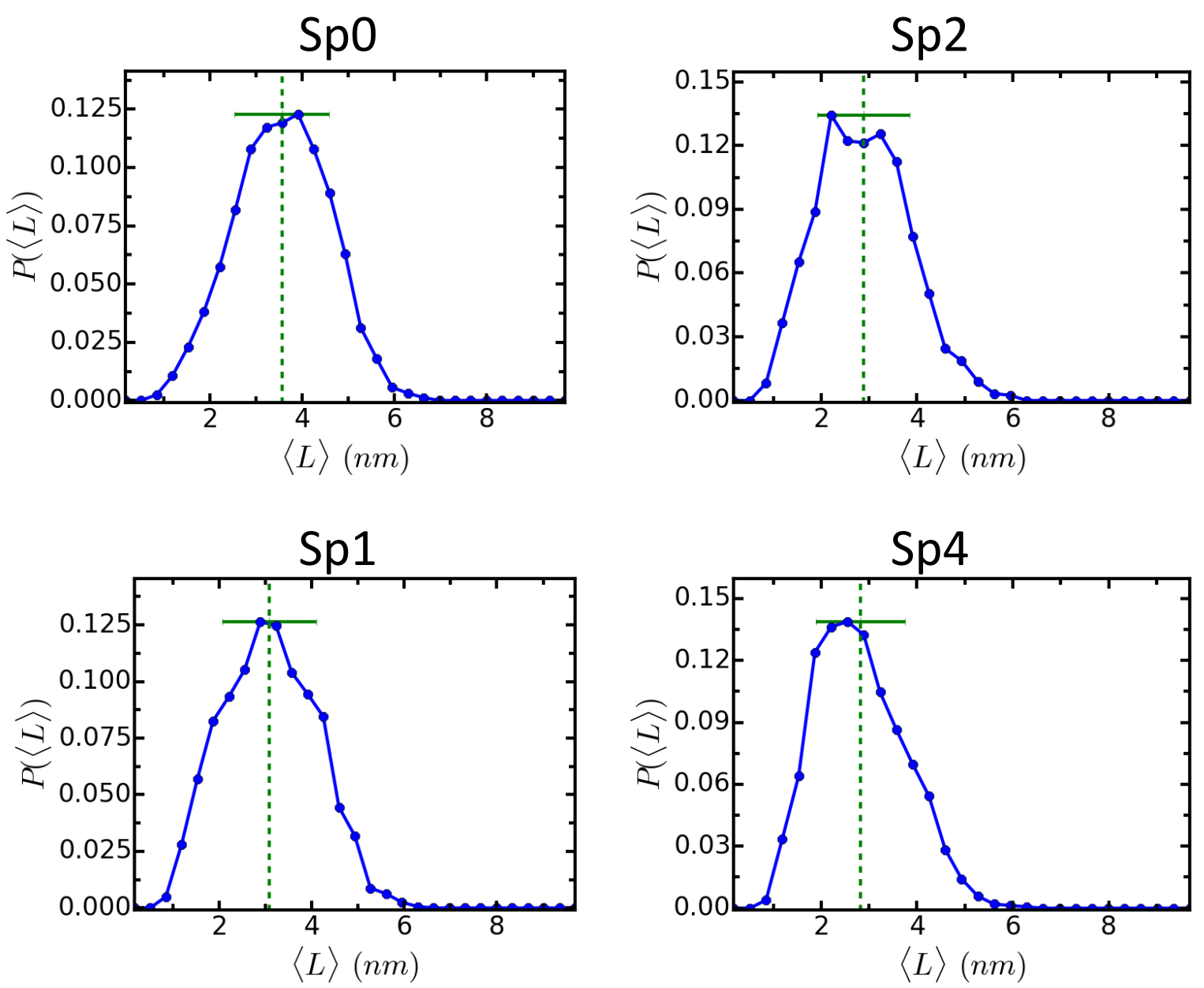

Figure S6: Average end-to-end distance $L$ for the unhybridized oligonucleotides of RNA-SNAS

The end-to-end distance $<\mathrm{L}>$ for the non-duplexed RNA shows that $\mathrm{Sp} 0$ (a) lengthens when no spacer is present. For the three other spacers $<\mathrm{L}>$ does not change in a statistically significant manner. The average value for $\mathrm{Sp} 0$ is $<\mathrm{L}>=3.71 \mathrm{~nm}$ (a). The average value for $\mathrm{Sp} 1, \mathrm{Sp} 2$, and $\mathrm{Sp} 4$ is $<\mathrm{L}>=3.00 \mathrm{~nm}$. 


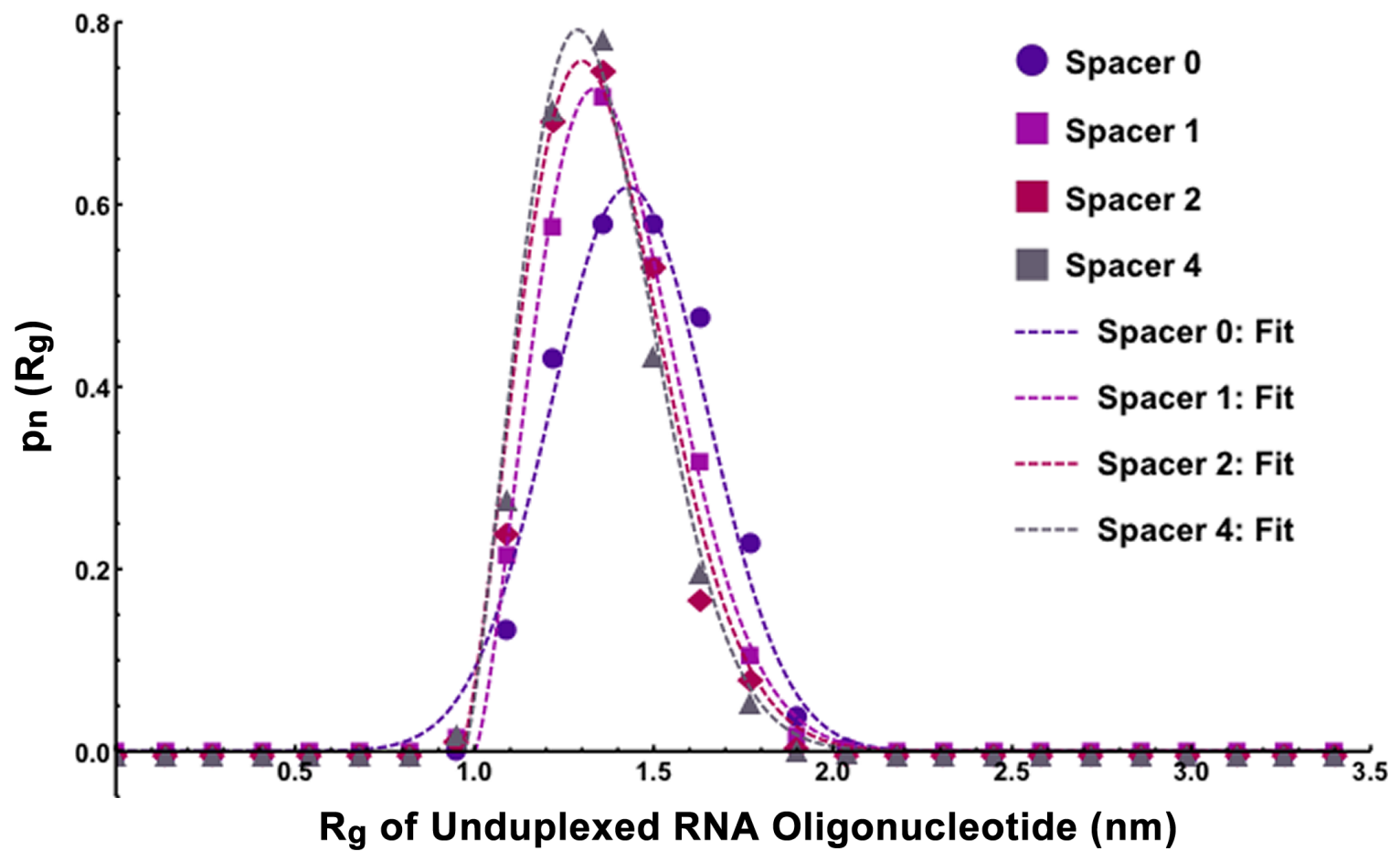

Figure S7: Probability distribution function (PDF) $p_{n}\left(R_{G}\right)$ of the radius of gyration $\left(R_{G}\right)$ of ssRNA for four different PEG spacers

PDF fits are taken from a generalized Gaussian generating function. 

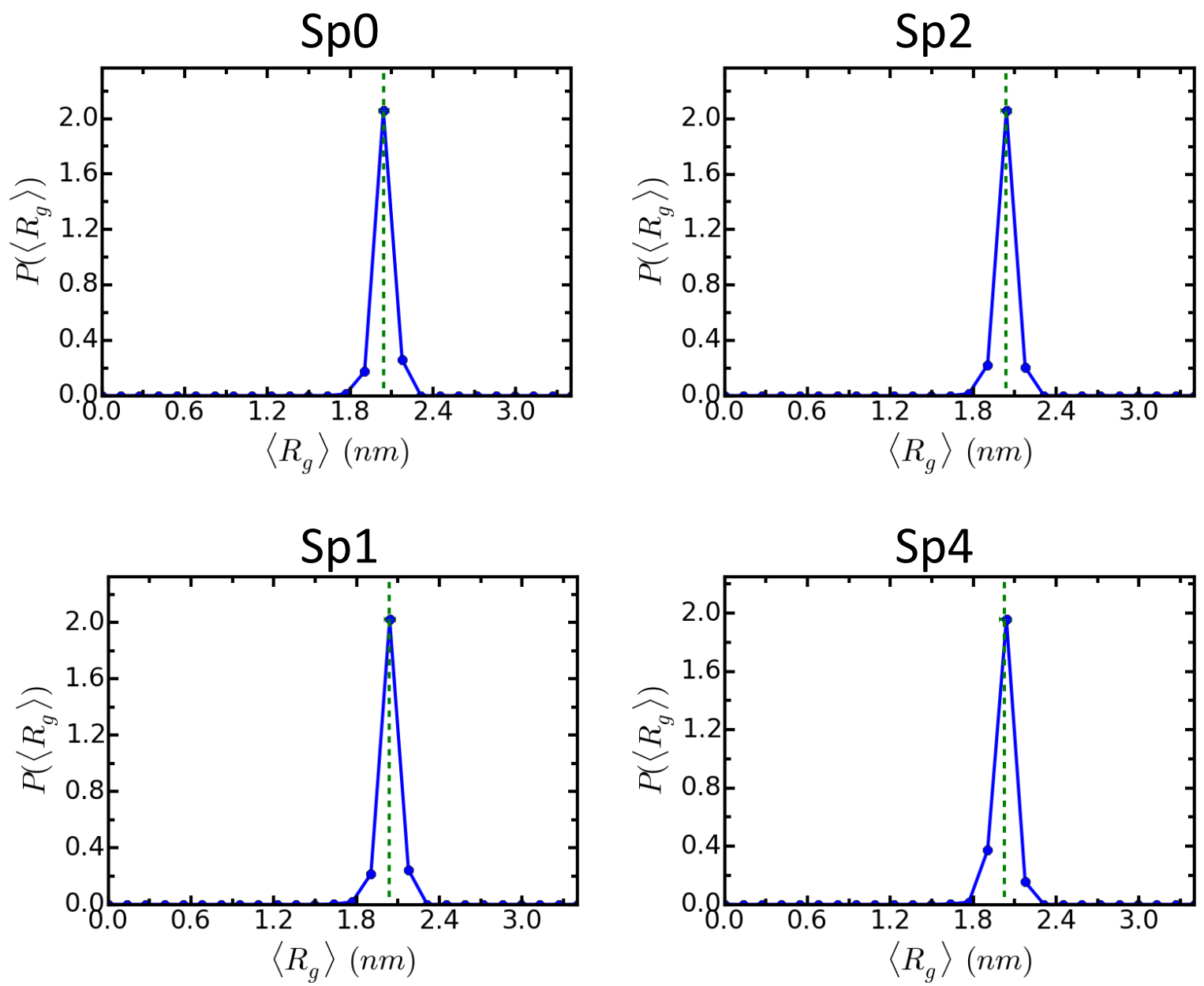

Figure S8: Radius of gyration $\left(R_{G}\right)$ for the hybridized oligonucleotides of RNA-SNAs

The radius of gyration for the duplexed RNA is independent of the number of spacers, as shown for $\mathrm{Sp} 0$ (a), $\mathrm{Sp} 1$ (b), $\mathrm{Sp} 2$ (c) and Sp4 (d). The average value is $\mathrm{R}_{\mathrm{g}}=1.98 \mathrm{~nm}$. 
a)

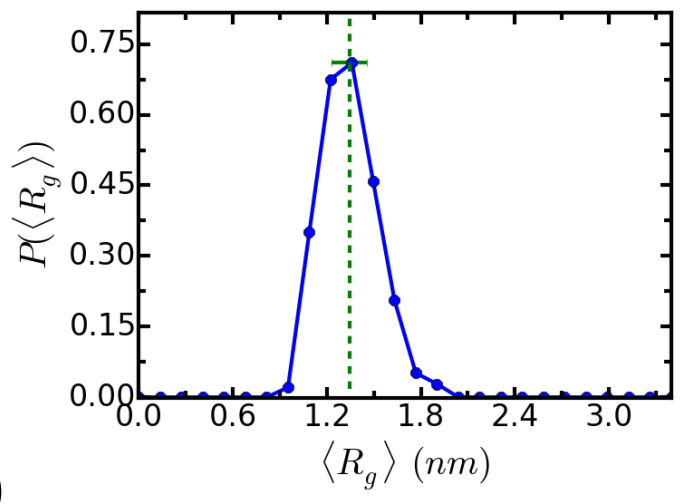

c)

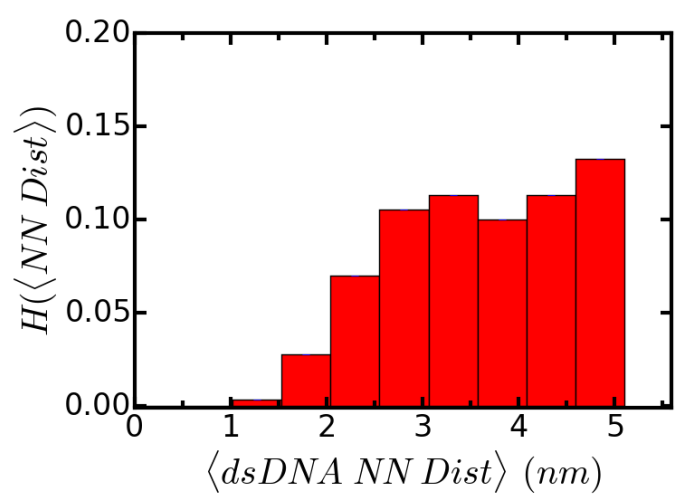

b)
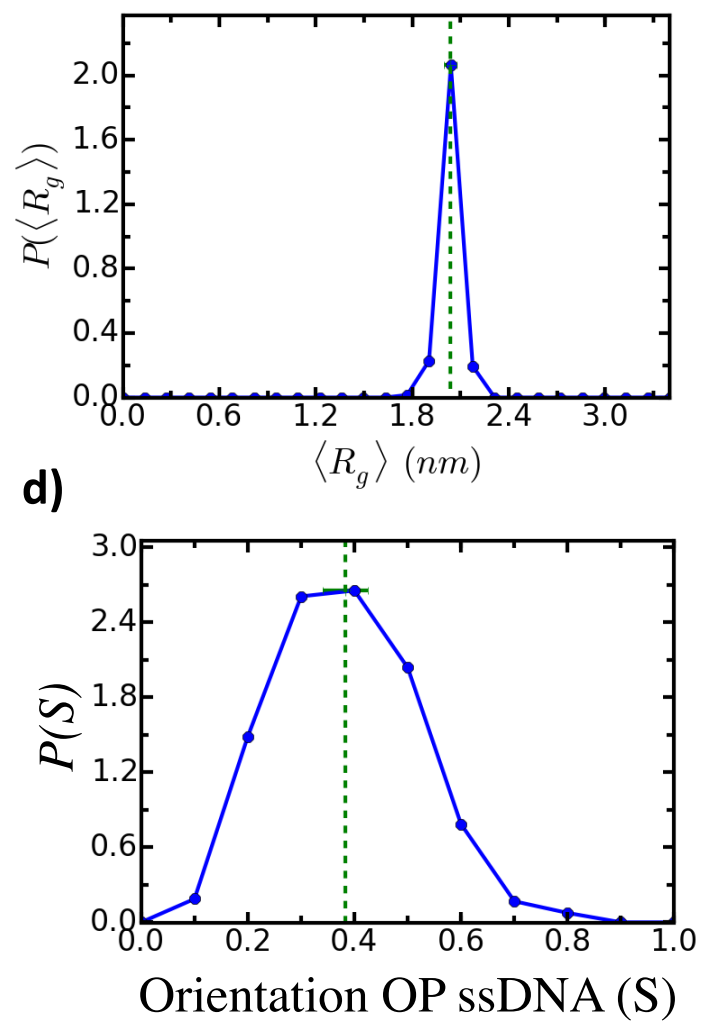

Figure S9: DNA-SNA structural data for 40 \% hybridized SNA
a) $\mathrm{Rg}$ for ssDNA
b) $\mathrm{Rg}$ for dsDNA
c) dsDNA neighbor histogram
d) Probability of orientational order via for ssDNA 


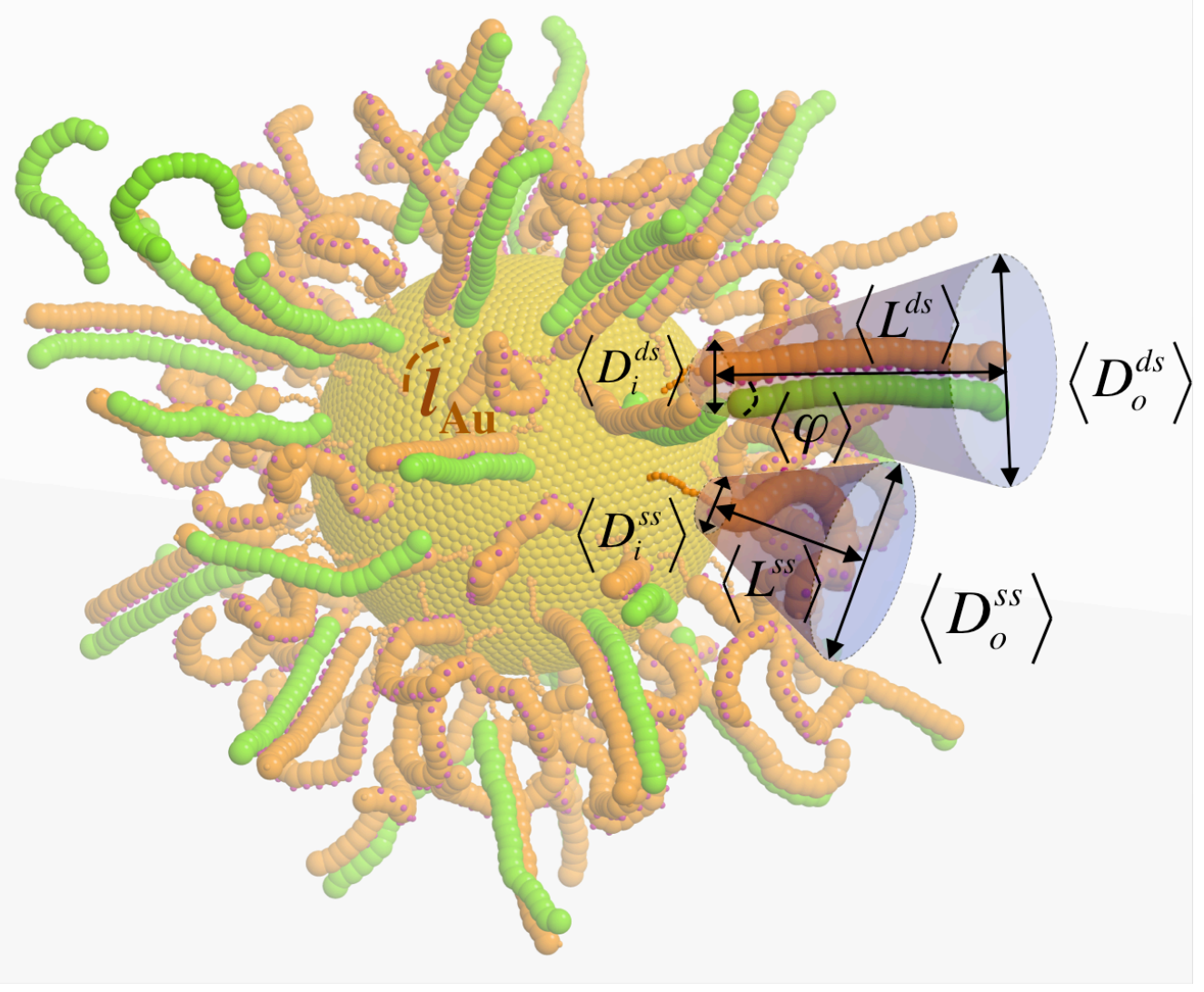

\section{Figure S10: Conical RNA structure model}

The dsRNA and ssRNA trace out conical frustums. The size parameters of the frustums are labeled as $\mathrm{L}_{\mathrm{y}}{ }^{\mathrm{x}}$ and $\mathrm{D}_{\mathrm{y}}{ }^{\mathrm{x}}$ where $\mathrm{y}$ is either (i)nner or (o)uter diameter and $\mathrm{x}$ is (ss)RNA or (ds)RNA. Additionally, the angle $\varphi$ represents deviation from the normal vector and $\cos \varphi$ is the $S$ order parameter. $l_{\mathrm{Au}}$ is the surface spacing of the nucleotides on the SNA. 


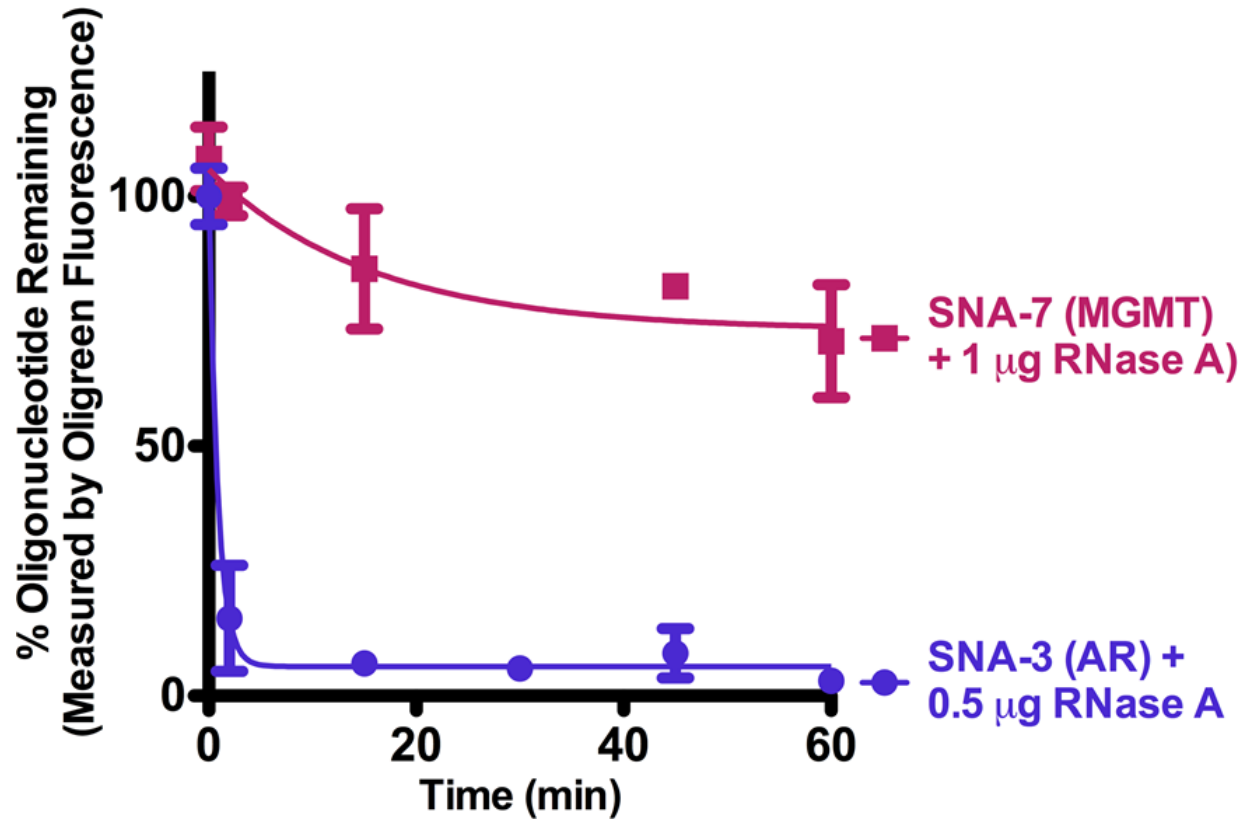

Figure S11: Interactions of RNA-SNAs with ribonuclease (RNase) A

SNAs-3 and 7 were incubated with solutions of RNase A in 1x PBS at $37{ }^{\circ} \mathrm{C}$, where analysis of the AS oligonucleotide over time revealed a similar trend to that observed for $10 \%$ FBS (Figure 2b). Data points were fit to first order decay functions. Error bars represent the standard deviation for $\mathrm{n}=2$ biological replicates. 

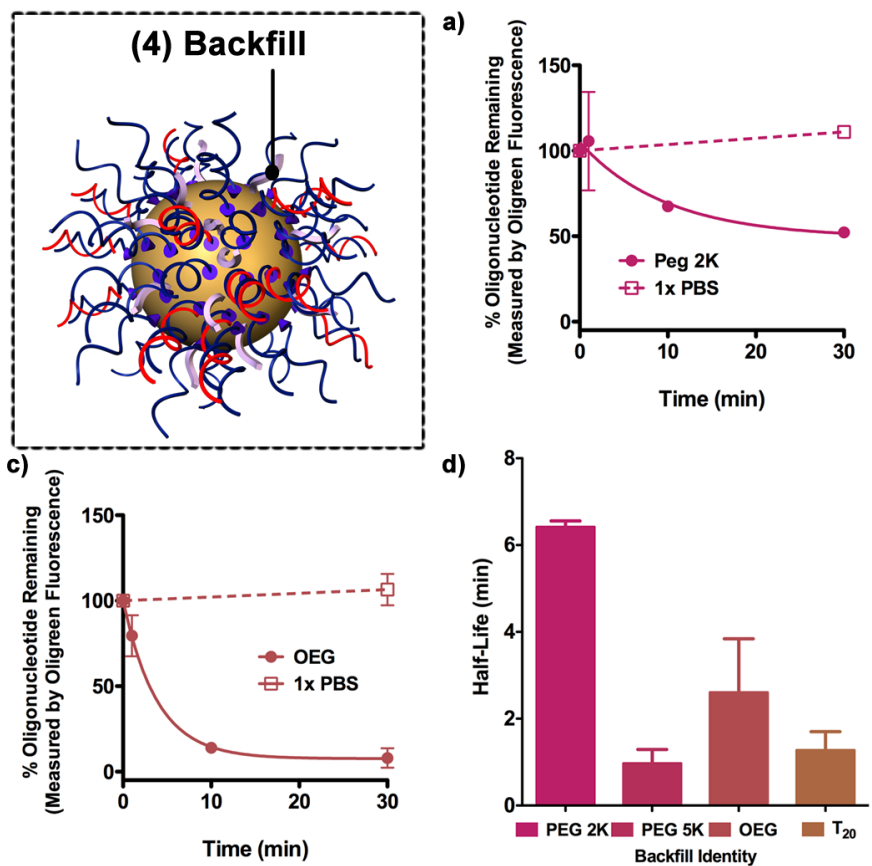

b)
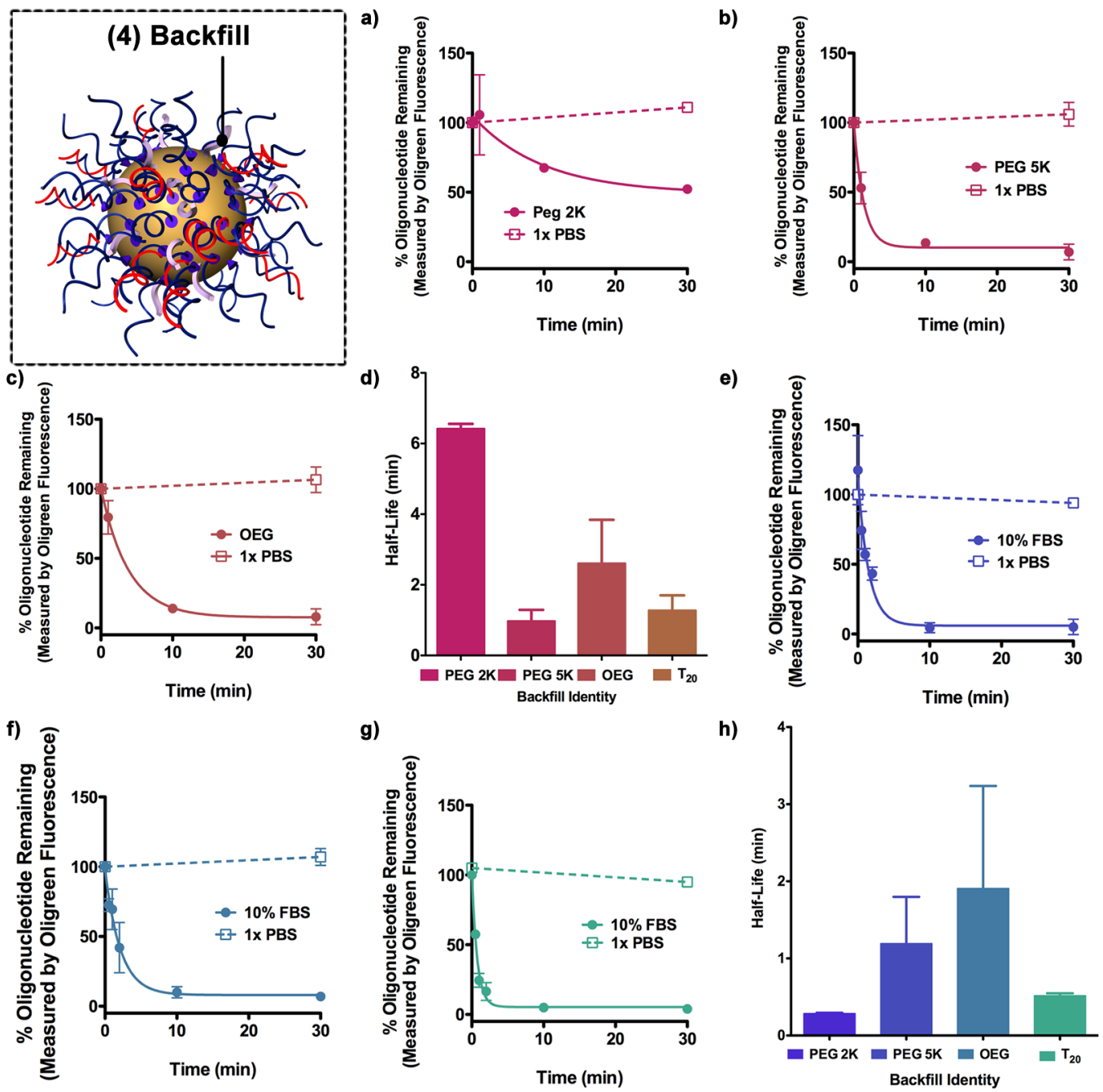

Figure S12: Effect of backfill on rate of nuclease- catalyzed hydrolysis

Stability of SNA-7 in 10\% FBS and 1x PBS with the following backfill molecules (6 hr incubation): (a) PEG 5K backfill, (b) OEG, and (c) $\mathrm{T}_{20}$. Data points were fit to a first order exponential decay function or a linear regression, respectively. The half-life was calculated from the first order exponential decay function and plotted in (d). To compare, the stability of SNA-3 with the following backfill molecules was also assessed: (e) PEG 5K backfill, (f) OEG, and (g) $\mathrm{T}_{20}$. The half-lives calculated from the first order exponential decay functions are plotted in (h). The data in (e) and (h; PEG 5K) is adapted from Barnaby et al. ${ }^{1}$ Error bars represent the standard deviation for $\mathrm{n}=2$ biological replicates. 


\section{MATERIALS AND METHODS.}

Preparation of Sterile, RNase-free Solutions

To prepare sterile solutions of water, 1x phosphate buffered saline (PBS; Corning), $5 \mathrm{M}$ sodium chloride (NaCl; Sigma Aldrich), $10 \mathrm{nM}$ AuNPs, and 10\% Tween-20 (Sigma Aldrich), $1 \mathrm{~mL}$ of diethylprocarbonate (DEPC; Sigma Aldrich) was added to $1 \mathrm{~L}$ of aforementioned solution. The mixture was then shaken at $50 \mathrm{rpm}$ for two hours at $45{ }^{\circ} \mathrm{C}$ before being autoclaved.

\section{RNA-Oligonucleotide Synthesis}

RNA oligonucleotides were synthesized using TOM-RNA phosphoramidites (ChemGenes) on a MerMade 12 system (Bioautomation) according to the manufacturerrecommended cleavage and deprotection protocols. All oligonucleotides were purified using reverse-phase high performance liquid chromatography (RP-HPLC) on a Varian Microsorb $\mathrm{C}_{18}$ column $(10 \mu \mathrm{M} ; 300 \times 10 \mathrm{~mm})$ with $0.1 \mathrm{M}$ triethylammonium acetate (TEAA) at $\mathrm{pH} 7$ with a $1 \%$ gradient of $100 \% \mathrm{CH}_{3} \mathrm{CN}$ at a flow rate of $3 \mathrm{~mL} / \mathrm{min}$, while monitoring the UV signal of the nucleic acids at $254 \mathrm{~nm}$. After purification, the oligonucleotides were lyophilized, re-suspended in sterile water, and stored at $-80^{\circ} \mathrm{C}$.

Synthesis of Spherical Nucleic Acid Nanoparticle Conjugates (RNA-SNA; Figure S1a)

SNAs were synthesized by modification of previously published methods. ${ }^{1,12}$ Gold nanoparticles (AuNPs) with 13-nm diameter were synthesized by modification of the Frens method, where chloroauric acid was reduced by sodium citrate in aqueous solution. ${ }^{13}$ To prepare duplex siRNA, the sense oligonucleotide (mRNA sequence targeted by the siRNA duplex; $150 \mathrm{mM}$ ) and anti-sense (AS) oligonucleotide (complementary to messenger RNA; $150 \mathrm{mM}$ ) were hybridized in a buffer consisting of $30 \mathrm{mM}$ HEPES and $100 \mathrm{mM}$ potassium acetate, $\mathrm{pH} 7.5$ (available from IDT) by first heating the solution to $95{ }^{\circ} \mathrm{C}$ for ten minutes, then cooling to $37{ }^{\circ} \mathrm{C}$ for sixty minutes while shaking at $350 \mathrm{rpm}$ in a thermomixer (Benchmark Scientific). Duplex siRNA was added to solutions of AuNPs $(10 \mathrm{nM})$ in $0.2 \%$ Tween-20 (v/v) and $150 \mathrm{mM} \mathrm{NaCl}$ (final concentration of $2 \mu \mathrm{M})$. The solution was then sonicated for thirty seconds and placed on a rotary shaker (Sigma Aldrich) for four hours, at which point the $\mathrm{NaCl}$ concentration was increased to $350 \mathrm{mM}$ and allowed to shake for 16 hours. The solution was then brought to $10 \mu \mathrm{M}$ in thiolated $2 \mathrm{kDa}$ polyethylene glycol (PEG; Nanocs) and allowed to shake for six hours (or in specified cases, 72 hours). The solution was then centrifuged for ten minutes in a swinging bucket rotor at $4000 \mathrm{rpm}$ in an Amicon Ultra-15 centrifugal filter unit (50 kDa cut-off; EMD Millipore). The flow-through was removed and the SNAs were washed twice with $0.01 \%$ Tween in $1 \mathrm{x}$ PBS by centrifugation at $4000 \mathrm{rpm}$ for ten minutes and removal of flow-through. The SNAs were then re-suspended in $1 \mathrm{~mL}$ of $0.01 \%$ Tween-20 in $1 \mathrm{x}$ PBS and centrifuged in an Eppendorf tube for 25 minutes at $15000 \mathrm{rpm}$. The supernatant was removed and the pellet was re-suspended in 1x PBS. The concentration of SNA was measured by absorbance at $520 \mathrm{~nm}\left(\mathrm{e}_{520 \mathrm{~nm}}=2.7 \cdot 10^{8} \mathrm{M}^{-1}\right.$ $\mathrm{cm}^{-1}$ ) using a Cary $5000 \mathrm{UV}-$ Vis. The SNAs were stored at $4{ }^{\circ} \mathrm{C}$ when not in use.

Synthesis of Spherical Nucleic Acid Nanoparticle Conjugates (RNA-SNA; Figure S1b)

SNAs were synthesized by modification of previously published methods ${ }^{1,12}$. Gold nanoparticles (AuNPs) with 13-nm diameter were synthesized by modification of 
the Frens method, where chloroauric acid was reduced by sodium citrate in aqueous solution. ${ }^{13}$ To prepare duplex siRNA, the sense oligonucleotide (mRNA sequence targeted by the siRNA duplex; $150 \mathrm{mM}$ ) and anti-sense (AS) oligonucleotide (complementary to messenger RNA; $150 \mathrm{mM}$ ) were hybridized in a buffer consisting of $30 \mathrm{mM}$ HEPES and $100 \mathrm{mM}$ potassium acetate, $\mathrm{pH} 7.5$ (available from IDT) by first heating the solution to $95{ }^{\circ} \mathrm{C}$ for ten minutes, then cooling to $37{ }^{\circ} \mathrm{C}$ for sixty minutes while shaking at $350 \mathrm{rpm}$ in a thermomixer (Benchmark Scientific). Duplex siRNA and PEG $2 \mathrm{~K}$ were added to solutions of AuNPs $(10 \mathrm{nM})$ in $0.2 \%$ Tween-20 (v/v) and 150 $\mathrm{mM} \mathrm{NaCl}$ (final concentration of $2 \mu \mathrm{M}$ ) at a ratio of 1:10 and 1:50 RNA:PEG 2K. The solution was then sonicated for thirty seconds and placed on a rotary shaker (Sigma Aldrich) for four hours, at which point the $\mathrm{NaCl}$ concentration was increased to $350 \mathrm{mM}$ and allowed to shake for 72 hours. The solution was then centrifuged for ten minutes in a swinging bucket rotor at $4000 \mathrm{rpm}$ in an Amicon Ultra-15 centrifugal filter unit $(50 \mathrm{kDa}$ cut-off; EMD Millipore). The flow-through was removed and the SNAs were washed twice with $0.01 \%$ Tween in $1 x$ PBS by centrifugation at $4000 \mathrm{rpm}$ for ten minutes and removal of flow-through. The SNAs were then re-suspended in $1 \mathrm{~mL}$ of $0.01 \%$ Tween-20 in $1 \mathrm{x}$ PBS and centrifuged in an Eppendorf tube for 25 minutes at $15000 \mathrm{rpm}$. The supernatant was removed and the pellet was re-suspended in 1x PBS. The concentration of SNA was measured by absorbance at $520 \mathrm{~nm}\left(\mathrm{e}_{520 \mathrm{~nm}}=2.7 \cdot 10^{8} \mathrm{M}^{-1} \mathrm{~cm}^{-1}\right)$ using a Cary $5000 \mathrm{UV}-\mathrm{Vis}$. The SNAs were stored at $4{ }^{\circ} \mathrm{C}$ when not in use.

\section{Free RNA Interaction with Serum Nucleases}

Pre-hybridized duplexes (150 $\mathrm{mM}$, prepared according to the method above) were incubated with serum nucleases $(1-50 \%)$ or control media (1x PBS) at a final concentration of $25 \mathrm{mM}$ at $37{ }^{\circ} \mathrm{C}$ or $20{ }^{\circ} \mathrm{C}$. At designated timepoints, $6 \mu \mathrm{L}$ of the reaction was quenched by pipetting it into $6 \mu \mathrm{L}$ of a quenching loading dye solution $(10 \%$ glycerol (Sigma Aldrich), 0.1\% SDS, $10 \mathrm{mM}$ dithiothreitol (Sigma Aldrich), and 1x nucleic acid running buffer (BioRad) in water). The mixture was vortexed and then analyzed using gel electrophoresis, as described below.

\section{Native 8\% Polyacrylamide Gel Electrophoresis (PAGE)}

A $500 \mathrm{~mL}$ gel stock was prepared with 240 grams of ultra-pure urea (Invitrogen), $100 \mathrm{~mL}$ of $40 \% 19: 1$ acrylamide/bis acrylamide (BioRad), $50 \mathrm{~mL}$ of 10x TAMg (450 $\mathrm{mM}$ Tris, $76 \mathrm{mM} \mathrm{MgCl} 2, \mathrm{pH}=8$ ) and brought to $500 \mathrm{~mL}$ using nanopure water for a final solution that is $8 \%$ acrylamide in $8 \mathrm{M}$ urea. The mixture was then stirred until clear. 220 $\mu \mathrm{L}$ Ammonium persulfate (at a concentration of $100 \mathrm{mg} / \mathrm{mL}$; Sigma Aldrich electrophoresis grade) was added to $30 \mathrm{~mL}$ of gel stock followed by the addition of $22 \mu \mathrm{L}$ of $N, N, N^{\prime}, N^{\prime}$ - Tetramethylethylenediamine (TEMED; BioRad). The solution was inverted $10 \mathrm{x}$ and then poured between two $16 \times 14 \mathrm{~cm}$ glass plates (Fisher Scientific) and allowed to polymerize for 30 minutes. The gel was then pre-run at $350 \mathrm{~V}$ for 10 minutes in $1 \mathrm{x}$ TAMg, after which the samples were loaded and separated by electrophoresis at $250 \mathrm{~V}$ for 35 hours. Following electrophoresis, the gel was rinsed with water and stained with 1x SYBR gold (Invitrogen) and imaged on a Fluorescence plate reader using a $473 \mathrm{~nm}$ blue laser. 


\section{Dynamic Light Scattering}

$100 \mu \mathrm{L}$ stock of $5 \mathrm{nM}$ of each sample was pipetted into ZEN0040 disposable cuvettes. The samples were sonicated prior to each individual DLS analysis. Samples were placed into the Malvern Zetasizer and incubated for 10 minutes at $37^{\circ} \mathrm{C}$. Each sample was then analyzed for 10 minutes each with 10 trials per sample.

\section{Molecular Dynamics Simulations}

Molecular Dynamics simulations were performed using the HOOMD-Blue simulation package. ${ }^{14}$ The NVT ensemble (with rigid body dynamics) ${ }^{11}$ was employed to thermodynamically sample the SNA-RNA at different hybridization amounts. For all the results in this paper, an excess of 50 cfRNA were in each cell. The simulation cell was kept fixed at $L=56.1 \mathrm{~nm}$ for all trajectories. The Coulombic forces were calculated using a pppm-Ewald summation ${ }^{15}$ to separate the long-range and short-range contributions. A short-range Ewald cut-off was set to $13.6 \AA$, and the mesh size was $3 \AA$. All calculations were done with a bulk salt concentration of $r_{\infty}=150 \mathrm{mM}$.

\section{References}

(1) Barnaby, S. N., Lee, A., and Mirkin, C. A. (2014) Probing the inherent stability of siRNA immobilized on nanoparticle constructs. Proc. Natl. Acad. Sci. USA 111, 9739-44.

(2) Hurst, S. J., Lytton-Jean, A. K., and Mirkin, C. A. (2006) Maximizing DNA loading on a range of gold nanoparticle sizes. Anal. Chem. 78, 8313-8.

(3) Pan, Y., and MacKerell Jr, A. D. (2003) Altered structural fluctuations in duplex RNA versus DNA: a conformational switch involving base pair opening. Nucleic Acids Res. 31, 7131-7140.

(4) Barnaby, S. N., Thaner, R. V., Ross, M. B., Brown, K. A., Schatz, G. C., and Mirkin, C. A. (2015) Modular and Chemically Responsive Oligonucleotide "Bonds" in Nanoparticle Superlattices. J. Am. Chem. Soc. 137, 13566-13571.

(5) Randeria, P. S., Jones, M. R., Kohlstedt, K. L., Banga, R. J., Olvera de la Cruz, M., Schatz, G. C., and Mirkin, C. A. (2015) What Controls the Hybridization Thermodynamics of Spherical Nucleic Acids? J. Am. Chem. Soc. 137, 3486-3489.

(6) Li, T. I. N. G., Sknepnek, R., and de la Cruz, M. O. (2013) Thermally Active Hybridization Drives the Crystallization of DNA-Functionalized Nanoparticles. $J$ Am Chem Soc 135, 8535-8541.

(7) Weeks, J. D., Chandler, D., and Andersen, H. C. (1971) Perturbation Theory of Thermodynamic Properties of Simple Liquids. J Chem Phys 55, 5422-+.

(8) Knorowski, C., Burleigh, S., and Travesset, A. (2011) Dynamics and Statics of DNA-Programmable Nanoparticle Self-Assembly and Crystallization. Phys Rev Lett 106.

(9) Kohlstedt, K. L., de la Cruz, M. O., and Schatz, G. C. (2013) Controlling Orientational Order in 1-D Assemblies of Multivalent Triangular Prisms. J Phys Chem Lett 4, 203-208.

(10) Knorowski, C., and Travesset, A. (2014) Self-Assembly and Crystallization of Hairy (f-Star) and DNA-Grafted Nanocubes. J Am Chem Soc 136, 653-659. 
(11) Nguyen, T. D., Phillips, C. L., Anderson, J. A., and Glotzer, S. C. (2011) Rigid body constraints realized in massively-parallel molecular dynamics on graphics processing units. Comput Phys Commun 182, 2307-2313.

(12) Giljohann, D. A., Seferos, D. S., Prigodich, A. E., Patel, P. C., and Mirkin, C. A. (2009) Gene Regulation with Polyvalent siRNA-Nanoparticle Conjugates. J. Am. Chem. Soc. 131, 2072-2073.

(13) Kimling, J., Maier, M., Okenve, B., Kotaidis, V., Ballot, H., and Plech, A. (2006) Turkevich Method for Gold Nanoparticle Synthesis Revisited. J. Phy. Chem. B 110, 15700-15707.

(14) Anderson, J. A., Lorenz, C. D., and Travesset, A. (2008) General purpose molecular dynamics simulations fully implemented on graphics processing units. J Comput Phys 227, 5342-5359.

(15) LeBard, D. N., Levine, B. G., Mertmann, P., Barr, S. A., Jusufi, A., Sanders, S., Klein, M. L., and Panagiotopoulos, A. Z. (2012) Self-assembly of coarse-grained ionic surfactants accelerated by graphics processing units. Soft Matter 8, 23852397. 